\title{
Application of gene therapy in auditory system diseases
}

\author{
Chunjiang $\mathrm{WEI}^{\mathrm{b}}$, Weijia KONG${ }^{\mathrm{b}^{*}}$, Zuhong $\mathrm{HE}^{\mathrm{a}, \mathrm{b}^{*}}$ \\ a Department of Pathology and Laboratory Medicine, Medical University of South Carolina, Charleston, SC 29425, USA. \\ ${ }^{b}$ Department of Otorhinolaryngology, Union Hospital, Tongji Medical College, Huazhong University of Science and Technology, Wuhan, China. \\ *Correspondence: entwjkong@hust.edu.cn; hezuhong@163.com \\ https://doi.org/10.37175/stemedicine.v1i1.17
}

\begin{abstract}
Prevention and treatment of auditory related diseases through genetic intervention is a hotspot in the field of hearing research in recent years. With the development of molecular technology, gene regulation has made a major breakthrough in the research of inner ear hair cell regeneration in recent years, which may provide us with a novel and efficient way to treat auditory related diseases. This review touches on the latest research on gene therapy in hereditary deafness, drug deafness, aging-related hearing loss, and noise-related hearing loss.
\end{abstract}

Keywords: Gene therapy $\cdot$ Hearing $\cdot$ Transfection vector $\cdot$ Auditory diseases $\cdot$ Inner ear

\section{Introduction}

Hearing loss is the most common sensory deficit in humans. Approximately 466 million people worldwide suffer from deafness, and the number is expected to increase to nearly 1 billion by 2050 (http://www.who.int/ mediacentre/factsheets/fs300/en/). In recent years, with the in-depth development of research on the pathogenesis of deafness, many researchers hope to improve or rescue hearing through gene therapy. We will introduce the research progress and new findings of gene therapy in hearing in this manuscript.

\section{Construction of animal models}

In order to better assess the efficiency, safety and therapeutic effects of gene transfection, it is necessary to construct a suitable animal model with a specific disease.

\section{Mammalian model}

Mice are one of the most commonly used models in mammals. At present, we have established a variety of mouse models of hearing loss induced by genes mutations to mimic some genetic mutations in human patients. However, the evolutionary relationship between mice and humans is relatively distant, and the biological differences are large. The ears of primate animals are more anatomically similar to humans, and they are more advantageous as animal models for gene therapy (1-3).

(C) The Author(s). 2019 This is an Open Access article distributed under the terms of the Creative Commons License (http://creativecommons.org/licenses/by/4.0/) which permits unrestricted use, distribution, and reproduction in any medium or format, provided the original work is properly cited.
Therefore, research on primate models has become a hotspot. Dai et al. evaluated whether the rhesus monkeys injected with sufficient amounts of fluid would suffer inner ear damage during the gene therapy process. The transfection conditions were optimized by comparing the transfection effects of the oval window stapedotomy pathway and the round window pathway (4). In addition, György et al. introduced the adeno-associated virus (AAV)-9 variant (aav9-php.b) into cynomolgus monkeys through round window membrane (RWM) and found that almost all of the inner and outer hair cells (HCs) were transfected. This is the first time that an AAV vector transfection assay has been performed on the inner ear of a primate (5).

\section{Non-mammal model}

Because non-mammals are genetically different from humans, they are rarely used in gene therapy research. However, the similarity between the zebrafish gene and the human gene is as high as $87 \%$. Previous studies have found that prps $1 a$ and prps $1 b$ in the zebrafish genome are very similar to the PRPS1 in the human genome, which provides support for zebrafish as a model for studying human hearing loss (6). In addition, the emergence of the CRISPR/CAS9 technology has made it possible to establish a model of hereditary hearing loss in zebrafish. In the latest report by Bing Zou et al., a zebrafish mariner mutant model was constructed using CRISPR/CAS9 (7).

\section{Application of gene transfection vectors}

Choosing the ideal gene transfection vector is a prerequisite for gene therapy. The ideal vector not only 
has high transfection efficiency in vivo, but also can accurately deliver DNA into target cells or tissues. In addition, whether the transfection intensity and time of the vector are controllable, whether it is safe and convenient for large-scale preparation are also factors for evaluation. At present, vectors are mainly divided into two major categories: viral vectors and non-viral vectors.

\section{Viral vectors}

Viral vectors include adenovirus, adeno-associated virus, helper-dependent adenovirus, herpes simplex virus, vaccinia virus, etc. Viral vectors are the most widely used vectors due to their high transfection efficiency. However, the traditional viral vector still has certain toxicity, and the gene carrying capacity is small. In recent years, more ideal viral vectors have been discovered through the mutation of AAV virus, which has improved the effectiveness and safety in specific applications, such as AAV2/ANC80L65 $(8,9)$, AAV-ie (10), and AAV9-PHP.B (11), etc (Figure 1).

\section{Non-viral vectors}

Non-viral gene vectors mainly include cationic liposomes, nanomaterials, etc. Compared with viral vectors, non-viral vectors are simple to prepare, low toxicity and do not induce host immune responses. Non-viral vectors have no restriction on the capacity of carrying genes, and can be modificated to obtain a variety of biological properties. However, the transfection efficiency of non-viral vectors is relatively low.

\section{Gene delivery pathway}

At present, the gene delivery pathways commonly used in animal experiments are as follows: (1) perforation in the cochlea; (2) perforation in semicircular canals; (3) injection of RWM; (4) infiltration of RWM. The choice of path depends mainly on factors such as the subject, the type of viral vector used, the transfection efficiency of the target cell and the degree of damage to the inner ear. In addition, the electroporation technology has been used as an alternative method for gene delivery in the inner ear in recent years, but it is still limited to in vitro tissue culture and gene therapy research in the uterus $(12,13)$.

\section{Gene therapy strategy}

Gene therapy mainly treats diseases through gene replacement, gene silencing, gene editing and $\mathrm{HC}$ regeneration. Gene replacement is the most direct way of gene therapy and is mainly used in the treatment of recessive hereditary diseases with mutation-induced phenotypic loss. For hereditary diseases associated with dominant inherited mutations, gene silencing via antisense oligonucleotide and RNA interference (RNAi) are mainly used for treatment. Currently, gene editing is mainly implemented using the CRISPR/CAS9 technology. It is the most advanced programmable nuclease for genome engineering and repair of targeted gene mutations.

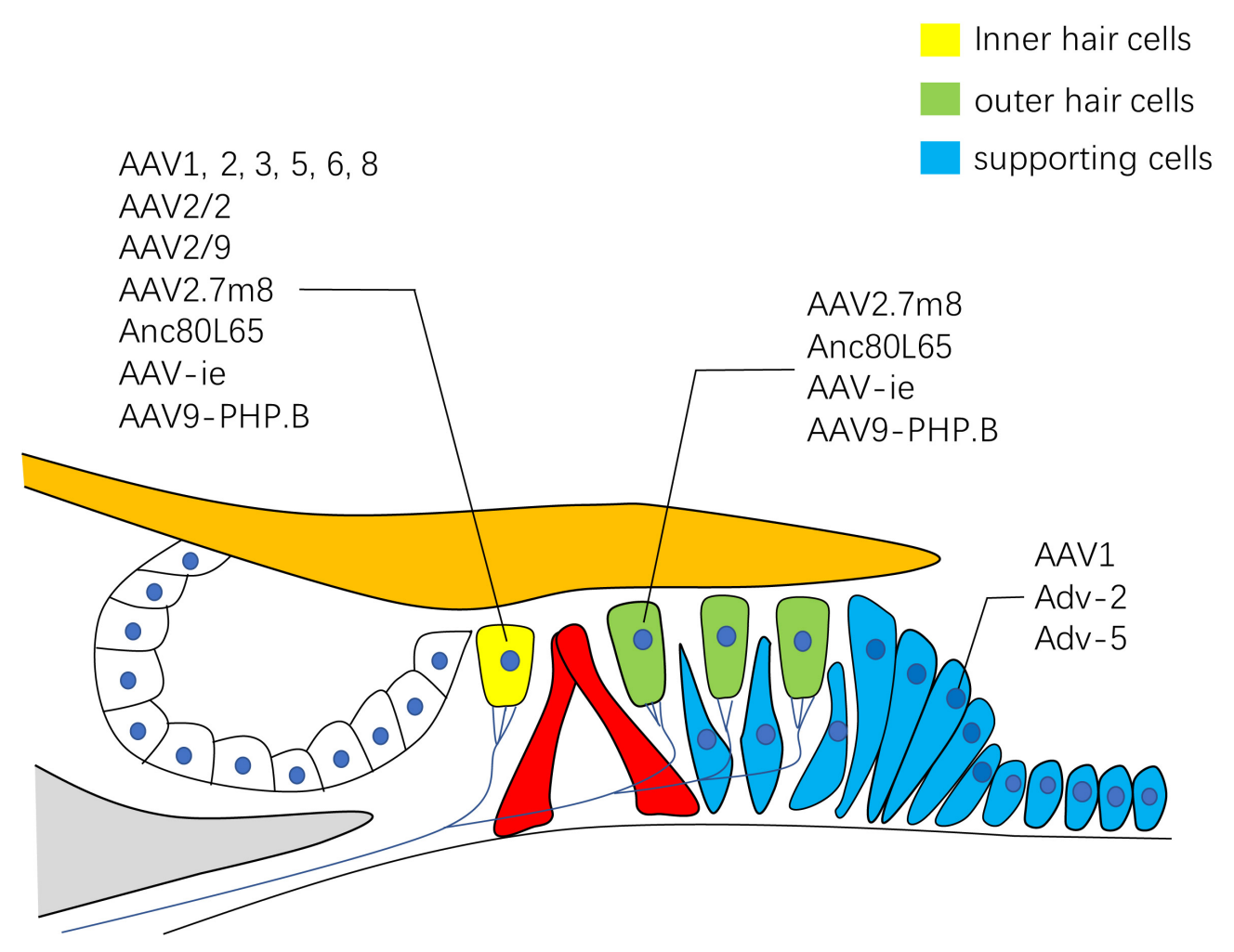

Figure 1. Viral vectors with specific transfection efficiency for different target cells. Studies have shown that AAV2.7m8, Anc80L65, AAV-ie, AAV9-PHP.B have high transfection efficiency in both inner hair cells and outer hair cells; AAV1, 2, 3, 5, 6, 8, AAV2/2, AAV2/9 also have higher transfection efficiency in inner hair cells, AAV1, Adv-2, Adv-5 have higher transfection efficiency in supporting cells; Adv: Adenovirus; AAV: adeno-associated virus. 
Finally, studies have shown that $\mathrm{HC}$ can be regenerated by modulating specific genes. Due to the damage of $\mathrm{HC}$ cells in most hearing-related diseases, it is suggested that $\mathrm{HC}$ regeneration methods will be widely used in hearing therapy in the future.

\section{Gene therapy in auditory diseases}

The sound perception and information transmission organs in the auditory system mainly include inner ear HCs, spiral ganglia neurons, and auditory central organs. The lesions of these cells or tissues can affect the perception and transmission of sound, and ultimately lead to hearing loss. Drug-induced deafness, sudden deafness, hereditary deafness, senile deafness, and noise deafness are clinically common types of sensorineural hearing loss. At present, the treatment of sensorineural hearing loss is mainly by wearing hearing aids and cochlear implants. Gene therapy is a biology-based intervention that does not require any device to reconstruct hearing. It is more convenient and economical for patients with sensorineural hearing loss. Therefore, gene therapy is very important for the treatment of sensorineural hearing loss.

\section{Gene therapy for hereditary deafness}

Hereditary deafness refers to hearing organ developmental disorders and hearing impairment due to abnormalities in genetic factors such as genes or chromosomes. Currently, more than one hundred non-syndromic hearing loss genes have been identified, including 71 autosomal recessive genes, 45 autosomal dominant genes, and 5 X-linked genes (https://www. hereditaryhearingloss.org). About $30 \%$ of hereditary hearing loss is associated with syndrome (14). There are currently 11 syndromes related to hearing loss, and there are 47 related genes, of which 27 are autosomal recessive, 13 are autosomal dominant, and 4 are autosomal dominant or recessive, 2 are $\mathrm{X}$-linked recessive inheritance (15). Human disease is modeled by establishing animal models of multiple hereditary deafness, followed by gene therapy and intervention. Gene therapy for hereditary deafness has made some progress. Current research results have shown that gene therapy was effective in animal models of multiple hereditary deafness and is expected to be clinically transformed in the future. The popular genes currently studied include Gjb2 (16), Vglut3 (17), Pou4f3 (18), Tmcl (19), Kcnq4 (20), Ushlc (21) and MsrB3 (22). In addition, some potential genes have recently been found to be associated with hearing loss, which may be the new direction of our research in the future, such as Clarin-2 (22, 23), Pls1 (24), Cldn9 (25), etc. However, there are some limitations in the current research involving neonatal mouse models. Mice mature after a few weeks of birth, whereas humans are welldeveloped at birth, so intervention on newborn mice is similar to intervention at the human fetal stage. To better mimic postnatal genetic deafness, we need to expand the time span of intervention. Recently, Yoshimura et al. reported on the study of the adult mice deafness model of Tmcl mutation. They injected microRNA into the cochlea via the $\mathrm{AAV}$ vector and showed that RNAi-mediated gene silencing inhibited hearing loss and increased survival of inner hair cells (IHC) (26). This result illustrates the feasibility of gene therapy in adult mouse models.

\section{Gene therapy for drug-induced deafness}

Drug-induced deafness is a sensorineural hearing loss caused by the application of antibiotics, antineoplastic drugs, etc. Common ototoxic drugs include aminoglycoside antibiotics and chemotherapeutic drugs such as cisplatin. For drug-induced deafness, there is still no optimized treatment yet. The best way to deal with drug-induced deafness is to reduce chances of its occurrence through early prevention. In recent years, drug deafness has been found to be associated with genetic variation, which may provide a reference for new treatments. Aminoglycoside antibiotics are commonly used antibiotics that often cause ototoxicity, leading to permanent $\mathrm{HC}$ loss and hearing damage. The ototoxic effects of aminoglycosides are related to oxidative stress. Studies have confirmed that antioxidant gene therapy has an inhibitory effect on aminoglycoside-induced oxidative stress in the inner ear, thereby promoting HC survival (27). Ototoxicity caused by cisplatin is a serious side effect in patients undergoing cisplatin therapy. However, ototoxicity caused by cisplatin shows significant differences among individuals, which may be due to different genetic backgrounds. Genomewide association studies (GWAS) have found that ACYP2 (28) and WFS1 (29) variants are closely related to cisplatin-induced ototoxicity, and some studies have reported SOD2 mutations associated with ototoxicity in cisplatin-treated children with medulloblastoma (30). Britt I. Drögemöller et al. have demonstrated that a variant of Slc16a5 is a novel genetic risk factor for testicular cancer patients. Silencing of Slc16a5 in vitro can alter cisplatin-induced cellular responses, suggesting that Slc16a5 plays a role in cisplatin-induced ototoxicity (31). Other studies have shown that overexpression of X-linked inhibitor of apoptosis protein in a mouse model also has an inhibitory effect on cisplatin-induced hearing loss (32-34).

\section{Gene therapy for senile deafness}

Senile deafness, also known as age-related hearing loss (ARHL), is a cumulative pathological and physiological change in the age-related auditory system. Senile deafness is a progressive and irreversible hearing loss, especially at high frequencies. According to the World Health Organization, senile deafness is the second most common disease among the elderly and the third most prevalent disease in the world. It is estimated that by 2025 , more than 500 million people will suffer from senile deafness. At present, the etiology of senile deafness is not very clear, and it is generally considered to be caused by interaction of various factors. A large number of studies have shown that mutations in some genes may increase the susceptibility to senile deafness. GWAS have been conducted to identify genes that may be associated with ARHL and found significant mutations in Prkce (35), Tgfbl (35), Nrf2 (35), Grm7 (36), and Cdh23 (37) in ARHL. In addition, mtDNA4977 (38), Nkccl (39), 
mucolipin 1 and 3 (40), $W f_{S} 1$ (41), Slc7a8 (42), Cox3, Gjb2 (43), Idh2 (44), neuropilin-1 (45), Igf1 (46, 47), Essrg (48), P2rx2 (49), Kcnq5 (49), Erbb3 (49), Socs3 (49), Slc26a4 (50), Spatcll (51), Bakl (52), Ccr3 (53) and Gilz (53) are also associated with ARHL, which may be potential target genes for the treatment of senile deafness by gene therapy in the future. In addition, in the research of animal models, it is found that activation of Sirt1 expression activates autophagy pathway, reduces $\mathrm{HC}$ death and hearing loss, and prevents the development of senile deafness (54). Senile deafness is closely related to the irreversible death of HCs. The treatment of senile deafness by the protection and regeneration of $\mathrm{HCs}$ has attracted the interest of many researchers. With the extensive development of HC regeneration research, a number of potential gene therapy targets have been discovered, the most representative of which is the Atohl gene. The Atohl gene is a transcriptional regulator required for $\mathrm{HC}$ differentiation. A number of animal studies have demonstrated that the overexpression of the Atohl gene in the inner ear can induce the transdifferentiation of the supporting cells (SCs) in the Corti to the HCs to achieve the purpose of $\mathrm{HC}$ regeneration in the cochlear and vestibular (55). At present, the intervention methods for senile deafness are still mainly to improve hearing, such as wearing hearing aids, but in the future, gene therapy is expected to be an effective method for treating ARHL.

\section{Gene therapy for noise deafness}

Noise-induced hearing loss (NIHL) is a slow progressive sensorineural deafness caused by prolonged exposure to noise stimuli. It is generally believed that the impairment of noise on hearing is related to the acoustic properties of the noise, the noise environment and individual conditions. Studies have shown that individuals' sensitivity to noiseinduced hearing loss is related to genetic factors. CAT, GSTM1, PON2, and SOD2 are significantly associated with activation of the oxidative stress pathway, while HSP70-1 and HSP70-2 mediated heat shock responses provide hearing protection in noise damage (56). It has also been highlighted that P2RX2 is an important protein that attenuates sound transmission in the context of highintensity noise (57). Noise can cause HC morphology change or even death, accompanied by degeneration of pillar cells, SCs, vascular streaks, peripheral nerve, and ganglion cells. Therefore, the protection and regeneration of hearing-related cells (such as $\mathrm{HCs}, \mathrm{SCs}$, etc.) is a key factor in the treatment of NIHL. In addition to the above-mentioned treatments using ATOH1 to induce $\mathrm{HC}$ regeneration, brain-derived neurotrophic factor (18) and neurotrophin-3 (NT3) (58) have been shown to promote the growth and maintenance of ribbon synapses and vestibular epithelium. Studies have found that upregulation of NT3 expression in postnatal mice can regenerate the ribbon synapses, thereby promoting the recovery of cochlear function after hearing injury (59). Although the current application of gene therapy to NIHL is still in the exploratory stage, it has detected significant hearing protection effects after inhibiting hearing loss susceptibility-related genes, up-regulating HC protectionrelated genes and $\mathrm{HC}$ regeneration-related genes.

\section{Conclusion}

Gene therapy in the field of hearing is a research hotspot in recent years. Although some progress has been made, most studies are still limited to cellular level or animal models. There are still many mechanisms for clinical transformation to explore. The current limitation of gene therapy is that animal models, gene vectors and delivery pathways need to be further optimized. In addition, current research on gene therapy mainly focuses on sensorineural deafness, but less on other diseases of the auditory system. Gene therapy has potential clinical application prospects, in addition to correcting gene mutations, protecting $\mathrm{HCs}$, SCs and spiral ganglion neurons from various damages, gene therapy may also induce $\mathrm{HC}$ regeneration. Currently, there are more than 2,500 clinical trials on gene therapy, including approved, ongoing, and completed, of which 2 are related to hearing treatment (https://clinicaltrials.gov/). With more and more hearing-related genes being identified and the development of gene therapy technology, more hearing-related clinical trials are expected to be conducted. Although gene therapy still faces various problems in the treatment of hearing disorders, in the future, this treatment will become a highly effective and safe treatment for hearing-impaired patients.

\section{Conflict of interest}

The authors declare no competing financial interests.

\section{References}

1. Guo W, Yi H, Ren L, Chen L, Zhao L, Sun W, et al. The morphology and electrophysiology of the cochlea of the miniature pig. Anat Rec (Hoboken). 2015;298(3):494-500.

2. Guo W, Yi H, Yan Z, Ren L, Chen L, Zhao LD, et al. The morphological and functional development of the stria vascularis in miniature pigs. Reprod Fertil Dev. 2017;29(3):585-93.

3. Ekdale EG. Comparative Anatomy of the Bony Labyrinth (Inner Ear) of Placental Mammals. PLoS ONE. 2013;8(6):e66624.

4. Dai C, Lehar M, Sun DQ, Rvt LS, Carey JP, MacLachlan T, et al. Rhesus cochlear and vestibular functions are preserved after inner ear injection of saline volume sufficient for gene therapy delivery. J Assoc. Res Otolaryngol. 2017;18(4):601-17.

5. György B, Meijer EJ, Ivanchenko MV, Tenneson K, Emond F, Hanlon KS, et al. Gene Transfer with AAV9-PHP.B rescues hearing in a mouse model of usher syndrome $3 \mathrm{~A}$ and transduces hair cells in a non-human primate. Mol Ther Methods Clin Dev. 2019;13:1-13.

6. DeSmidt AA, Zou B, Grati M, Yan D, Mittal R, Yao Q, et al. Zebrafish model for nonsyndromic $X$-linked sensorineural deafness, DFNX1. Anat Rec (Hoboken). 2019.

7. Zou B, Desmidt AA, Mittal R, Yan D, Richmond M, Tekin M, et al. The generation of zebrafish mariner model using the CRISPR/Cas9 system. Anat Rec (Hoboken). 2019.

8. Suzuki J, Hashimoto K, Xiao R, Vandenberghe LH, Liberman MC. Cochlear gene therapy with ancestral AAV in adult mice: complete transduction of inner hair cells without cochlear dysfunction. Sci Rep. 2017;7:45524.

9. Gu X, Chai R, Guo L, Dong B, Li W, Shu Y, et al. Transduction of adeno-associated virus vectors targeting hair cells and 
supporting cells in the neonatal mouse cochlea. Front Cell Neurosci. 2019;13:8.

10. Tan F, Chu C, Qi J, Li W, You D, Li K, et al. AAV-ie enables safe and efficient gene transfer to inner ear cells. Nat Commun. 2019;10(1):3733.

11. Giannelli SG, Luoni M, Castoldi V, Massimino L, Cabassi $\mathrm{T}$, Angeloni D, et al. Cas9/sgRNA selective targeting of the $\mathrm{P} 23 \mathrm{H}$ Rhodopsin mutant allele for treating retinitis pigmentosa by intravitreal AAV9.PHP.B-based delivery. Hum Mol Genet. 2018;27(5):761-79.

12. Driver EC, Kelley MW. Transfection of mouse cochlear explants by electroporation. Curr Protoc Neurosci. 2010; Chapter 4:Unit 4.34.1-10

13. Wang $L$, Jiang $H$, Brigande JV. Gene transfer to the developing mouse inner ear by in vivo electroporation. J Vis Exp. 2012(64).

14. Hilgert N, Smith RJ, Van Camp G. Function and expression pattern of nonsyndromic deafness genes. Curr Mol Med. 2009;9(5):546-64

15. Carpena NT, Lee MY. Genetic Hearing Loss and Gene Therapy. Genomics Inform. 2018;16(4):e20.

16. lizuka T, Kamiya K, Gotoh S, Sugitani Y, Suzuki M, Noda $T$, et al. Perinatal Gjb2 gene transfer rescues hearing in a mouse model of hereditary deafness. Hum Mol Genet. 2015;24(13):3651-61.

17. Akil O, Seal RP, Burke K, Wang C, Alemi A, During M, et al Restoration of hearing in the VGLUT3 knockout mouse using virally mediated gene therapy. Neuron. 2012;75(2):283-93.

18. Fukui H, Wong HT, Beyer LA, Case BG, Swiderski DL, D Polo $A$, et al. BDNF gene therapy induces auditory nerve survival and fiber sprouting in deaf Pou4f3 mutant mice. Sc Rep. 2012;2:838.

19. Nist-Lund CA, Pan B, Patterson A, Asai Y, Chen T, Zhou $\mathrm{W}$, et al. Improved TMC1 gene therapy restores hearing and balance in mice with genetic inner ear disorders. Nat Commun. 2019;10(1):236.

20. Kesser BW, Hashisaki GT, Holt JR. Gene transfer in human vestibular epithelia and the prospects for inner ear gene therapy. Laryngoscope. 2008;118(5):821-31.

21. Pan B, Askew C, Galvin A, Heman-Ackah S, Asai Y Indzhykulian AA, et al. Gene therapy restores auditory and vestibular function in a mouse model of Usher syndrome type 1c. Nat Biotechnol. 2017;35(3):264-72.

22. Kim MA, Cho HJ, Bae SH, Lee B, Oh SK, Kwon TJ, et al. Methionine sulfoxide reductase B3-targeted in utero gene therapy rescues hearing function in a mouse model of congenital sensorineural hearing loss. Antioxid Redox Signal. 2016;24(11):590-602.

23. Dunbar LA, Patni P, Aguilar C, Mburu P, Corns L, Wells $H R$, et al. Clarin-2 is essential for hearing by maintaining stereocilia integrity and function. EMBO Mol Med. 2019;11(9):e10288.

24. Morgan A, Koboldt DC, Barrie ES, Crist ER, García García $\mathrm{G}$, Mezzavilla M, et al. Mutations in PLS1, encoding fimbrin, cause autosomal dominant nonsyndromic hearing loss. Human mutation. 2019.

25. Sineni CJ, Yildirim-Baylan M, Guo S, Camarena V, Wang G, Tokgoz-Yilmaz S, et al. A truncating CLDN9 variant is associated with autosomal recessive nonsyndromic hearing loss. Hum Mutat. 2019;138(10):1071-5.

26. Yoshimura H, Shibata SB, Ranum PT, Moteki H, Smith RJH. Targeted allele suppression prevents progressive hearing loss in the mature murine model of human TMC1 deafness. Molecular therapy : the journal of the American Society of Gene Therapy. 2019;27(3):681-90.

27. Kawamoto K, Sha SH, Minoda R, Izumikawa M, Kuriyama $\mathrm{H}$, Schacht J, et al. Antioxidant gene therapy can protect hearing and hair cells from ototoxicity. Mol Ther. 2004;9(2):173-81.

28. Xu H, Robinson GW, Huang J, Lim JY, Zhang H, Bass JK, et al. Common variants in ACYP2 influence susceptibility to cisplatin-induced hearing loss. Nat Genet. 2015;47(3):263-6. 29. Wheeler HE, Gamazon ER, Frisina RD, Perez-Cervantes C, El Charif O, Mapes B, et al. Variants in and other mendelian deafness genes are associated with cisplatin-associated ototoxicity. Clin Cancer Res. 2017;23(13):3325-33.

30. Brown AL, Lupo PJ, Okcu MF, Lau CC, Rednam S, Scheurer ME. SOD2 genetic variant associated with treatment-related ototoxicity in cisplatin-treated pediatric medulloblastoma. Cancer Med. 2015;4(11):1679-86.

31. Drögemöller BI, Monzon JG, Bhavsar AP, Borrie AE, Brooks $B$, Wright GEB, et al. Association between SLC16A5 genetic variation and cisplatin-induced ototoxic effects in adult patients with testicular cancer. JAMA Oncol. 2017;3(11):1558-62.

32. Cooper LB, Chan DK, Roediger FC, Shaffer BR, Fraser JF, Musatov $S$, et al. AAV-mediated delivery of the caspase inhibitor XIAP protects against cisplatin ototoxicity. Otol Neurotol. 2006;27(4):484-90.

33. Jie H, Tao S, Liu L, Xia L, Charko A, Yu Z, et al. Cochlear protection against cisplatin by viral transfection of $X$-linked inhibitor of apoptosis protein across round window membrane. Gene Ther. 2015;22(7):546-52.

34. Chan DK, Lieberman DM, Musatov S, Goldfein JA, Selesnick $\mathrm{SH}$, Kaplitt MG. Protection against cisplatin-induced ototoxicity by adeno-associated virus-mediated delivery of the X-linked inhibitor of apoptosis protein is not dependent on caspase inhibition. Otol Neurotol. 2007;28(3):417-25.

35. Fetoni AR, Zorzi V, Paciello F, Ziraldo G, Peres C, Raspa M, et al. Cx26 partial loss causes accelerated presbycusis by redox imbalance and dysregulation of Nfr2 pathway. Redox Biol. 2018;19:301-17.

36. Newman DL, Fisher LM, Ohmen J, Parody R, Fong CT, Frisina ST, et al. GRM7 variants associated with age-related hearing loss based on auditory perception. Hear Res. 2012;294(1-2):125-32.

37. Wang T, Yang J, Ji X, Chu M, Zhang R, Dai J, et al. Pathway analysis for a genome-wide association study of pneumoconiosis. Toxicol Lett. 2015;232(1):284-92.

38. Ueda N, Oshima T, Ikeda K, Abe K, Aoki M, Takasaka T. Mitochondrial DNA deletion is a predisposing cause for sensorineural hearing loss. Laryngoscope. 1998;108(4 Pt 1):580-4.

39. Liu Y, Chu H, Chen J, Zhou L, Chen Q, Yu Y, et al. Agerelated change in the expression of NKCC1 in the cochlear lateral wall of C57BL/6J mice. Acta Otolaryngol. 2014;134(10):1047-51.

40. Wiwatpanit T, Remis NN, Ahmad A, Zhou Y, Clancy JC Cheatham MA, et al. Codeficiency of lysosomal mucolipins 3 and 1 in cochlear hair cells diminishes outer hair cell longevity and accelerates age-related hearing loss. J Neurosci. 2018;38(13):3177-89.

41. Kytövuori L, Hannula S, Mäki-Torkko E, Sorri M, Majamaa K. A nonsynonymous mutation in the WFS1 gene in a Finnish family with age-related hearing impairment. Hear Res. 2017;355:97-101.

42. Espino Guarch M, Font-Llitjós M, Murillo-Cuesta S, ErrastiMurugarren E, Celaya AM, Girotto G, et al. Mutations inLtype amino acid transporter-2 support as a novel gene involved in age-related hearing loss. ELife. 2018;7.

43. Lin X, Li G, Zhang Y, Zhao J, Lu J, Gao Y, et al. Hearing consequences in Gjb2 knock-in mice: implications for human p.V37I mutation. Aging. 2019;11(18):7416-41.

44. White K, Kim MJ, Han C, Park HJ, Ding D, Boyd K, et al. Loss of IDH2 accelerates age-related hearing loss in male mice. Sci Rep. 2018;8(1):5039.

45. Salehi P, Ge MX, Gundimeda U, Michelle Baum L, Lael Cantu H, Lavinsky J, et al. Role of neuropilin-1/semaphorin$3 \mathrm{~A}$ signaling in the functional and morphological integrity of the cochlea. PLoS Genet. 2017;13(10):e1007048.

46. Paulsen AJ, Cruickshanks KJ, Pinto A, Schubert CR, Dalton DS, Fischer ME, et al. Neuroprotective factors and incident hearing impairment in the epidemiology of hearing loss study. 
Laryngoscope. 2019;129(9):2178-83.

47. Riquelme R, Cediel R, Contreras J, la Rosa Lourdes RD, Murillo-Cuesta S, Hernandez-Sanchez C, et al. A comparative study of age-related hearing loss in wild type and insulin-like growth factor I deficient mice. Front Neuroanat. 2010;4:27.

48. Nolan LS, Maier H, Hermans-Borgmeyer I, Girotto G, Ecob $\mathrm{R}$, Pirastu N, et al. Estrogen-related receptor gamma and hearing function: evidence of a role in humans and mice. Neurobiol Aging. 2013;34(8):2077.e1-9.

49. Bouzid A, Smeti I, Dhouib L, Roche M, Achour I, Khalfallah A, et al. Down-expression of P2RX2, KCNQ5, ERBB3 and SOCS3 through DNA hypermethylation in elderly women with presbycusis. Biomarkers. 23(4):347-56.

50. Xu J, Zheng J, Shen W, Ma L, Zhao M, Wang X, et al. Elevated SLC26A4 gene promoter methylation is associated with the risk of presbycusis in men. Mol Med Rep. 2017;16(1):347-52.

51. Morgan A, Vuckovic D, Krishnamoorthy N, Rubinato E, Ambrosetti $U$, Castorina $P$, et al. Next-generation sequencing identified SPATC1L as a possible candidate gene for both early-onset and age-related hearing loss. Eur J Hum Genet. 2019;27(1):70-9.

52. Falah $M$, Najafi $M$, Houshmand $M$, Farhadi $M$. Expression levels of the BAK1 and BCL2 genes highlight the role of apoptosis in age-related hearing impairment. Clin Interv
Aging. 2016;11:1003-8.

53. Dong $\mathrm{Y}$, Li M, Liu P, Song H, Zhao Y, Shi J. Genes involved in immunity and apoptosis are associated with human presbycusis based on microarray analysis. Acta Otolaryngol. 2014;134(6):601-8.

54. Pang J, Xiong H, Ou Y, Yang H, Xu Y, Chen S, et al. SIRT1 protects cochlear hair cell and delays age-related hearing loss via autophagy. Neurobiol Aging. 2019;80:127-37.

55. Izumikawa M, Minoda R, Kawamoto K, Abrashkin KA, Swiderski DL, Dolan DF, et al. Auditory hair cell replacement and hearing improvement by Atoh1 gene therapy in deaf mammals. Nat Med. 2005;11(3):271-6.

56. Clifford RE, Hoffer M, Rogers R. The genomic basis of noise-induced hearing loss: a literature review organized by cellular pathways. Otol Neurotol. 2016;37(8):e309-16.

57. Housley GD, Morton-Jones R, Vlajkovic SM, Telang RS, Paramananthasivam V, Tadros SF, et al. ATP-gated ion channels mediate adaptation to elevated sound levels. Proc Natl Acad Sci USA. 2013;110(18):7494-9.

58. Chen H, Xing Y, Xia L, Chen Z, Yin S, Wang J. AAVmediated NT-3 overexpression protects cochleae against noise-induced synaptopathy. Gene Ther. 2018;25(4):251-9.

59. Wan G, Gómez-Casati ME, Gigliello AR, Liberman MC, Corfas G. Neurotrophin-3 regulates ribbon synapse density in the cochlea and induces synapse regeneration after acoustic trauma. ELife. 2014;3. 